\title{
Non-alcoholic fatty liver disease and metabolic syndrome in Brazilian middle-aged and older adults
}

\author{
Stricto sensu postgraduate program in Gerontology, Universidade Católica \\ de Brasilia (UCB), Taguatinga, Federal District, Brazil
}

\section{INTRRDUCTION}

Non-alcoholic fatty liver disease (NAFLD) is a clinicopathological syndrome that ranges from simple steatosis to steatohepatitis, fibrosis or cirrhosis. It is characterized by diffuse or focal fat accumulation in the hepatic parenchyma of patients who deny any history of abusive alcohol consumption. ${ }^{1}$ NAFLD may progress to end-stage liver disease and hepatocellular carcinoma. ${ }^{2}$ It is not possible to predict accurately which patients are at risk of progression and development of associated liver complications, but age is increasingly recognized as a predisposing element. ${ }^{3}$

The onset of the fatty liver phenotype is not well understood, and the leading physiopathological hypothesis links consumption of fat-rich foods and hepatic fat accumulation due to insulin resistance. ${ }^{2,3}$ Insulin resistance, together with obesity, hypertension and dyslipidemia, constitute a state of cardiovascular risk that is defined as metabolic syndrome. The understanding that metabolic disorders are prevalent among the elderly and the lack of reliable estimates in the literature on the prevalence of NAFLD in Brazil are valid justifications for studies on the natural history of the idiopathic steatotic manifestation of NAFLD and its associated metabolic conditions among the elderly population in Brazil.

\section{口BJECTIVE}

The aim of this study was to assess the occurrence of idiopathic NAFLD in a sample of community-dwelling middle-aged and older adults living in the Brazilian Federal District, and to evaluate its association with individual components of metabolic syndrome and with the syndrome as a whole.

METHODS

The present cross-sectional study was performed using data on 177 people living in urban areas on the outskirts of the Brazilian Federal District who were aged 55 years or older at the time of the study. These individuals were recruited to undergo health screenings at the Universidade Católica de Brasília (UCB) between August 2003 and April 2004. This was a non-probabilistic, convenience sample of consecutive cases.

NAFLD was diagnosed by means of a protocol that brought together clinical, laboratory and ultrasound examinations. Medical examinations were conducted to exclude individuals exhibiting clinical signs of active or past liver infection, inflammation or malignancies; to avoid patients with abusive alcohol consumption on the basis of the history provided; and to rule out any influence from hepatotoxic drugs. On admission, each subject was examined by means of a medical procedure adapted from Bellentani et al., ${ }^{4}$ which is briefly described in the following: i) detailed medical history of any acute hepatitis, surgery and drug or alcohol abuse, and also any history of previous diagnoses of cirrhosis, hemochromatosis or any congenital liver disease; ii) careful investigation of any current sign of liver or biliary disease, with emphasis on right upper quadrant pain, jaundice, malaise, anorexia, nausea, vomiting, scleral icterus, palmar erythema, ascites, hepatomegaly, splenomegaly and thrombocytopenia; and iii) detailed inventory of drugs in use or used within the last six months prior to the study, with emphasis on drugs with known hepatotoxicity.

The alcohol consumption history, recumbent blood pressure and medications in use were independently assessed by a physician and a nutritionist from their respective interviews with each patient and, whenever possible, these data were checked with family members. These were confirmed at least once by the physician, at a third, independent consultation prior to the ultrasound session. The

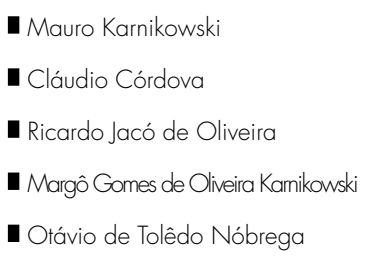

\section{ABSTRACT}

CONTEXT AND OBJECTIVES: Non-alcoholic fatty liver disease (NAFLD) is a complex clinicopathological entity characterized by diffuse or focal fat accumulation in the hepatic parenchyma of patients who deny abusive alcohol consumption. This study aimed to assess idiopathic NAFLD in community-dwelling, middle-aged and older adults living in the Brazilian Federal District. Associations between NAFLD and components of metabolic syndrome and the whole syndrome were investigated.

DESIGN AND SETTINGS: This was a cross-sectional study on 139 subjects aged 55 years or older.

METHODS: NAFLD was diagnosed by means of clinical procedures, to exclude subjects with signs of liver disorders, abusive alcohol consumption and influence from hepatotoxic drugs. Phenotypes were graded based on ultrasound examination. Metabolic syndrome was defined using the NCEP ATP III criteria. Laboratory tests were performed to assist clinical examinations and define the syndrome.

RESULTS: NAFLD was present in $35.2 \%$ of the subjects. Taken together, the two most intense phenotypes correlated with increased serum fasting glucose, triglyceride and VLDL cholesterol levels. Metabolic syndrome was diagnosed in $25.9 \%$ of the sample. In addition to associating NAFLD with specific traits of metabolic syndrome, non-parametric analysis confirmed the existence of a relationship $(p<0.05)$ between the steatotic manifestation and the syndromic condition.

CONCLUSION: Compared with the literature, this study reveals greater frequency of idiopathic NAFLD among Brazilian middle-aged and older adults than is described elsewhere. The findings also suggest that impaired glycemic metabolism coupled with increased fat delivery and/or sustained endogenous biosynthesis is the most likely physiopathogenic mechanisms underlying the onset of NAFLD in this population.

KEY WORDS: Fatty liver. Aged. Middle aged. Metabolic syndrome X. Brazil. 
amounts of alcohol consumed were derived from the history of alcoholic beverages consumed, frequency of drinking per week and volume of drinking per day. Men and women who consumed less than 30 or 20 grams of alcohol/day, respectively, over the last two years were considered to be non-drinkers. The nutritional consultation also had the aim of obtaining the waist circumference, to allow blind identification of individuals with metabolic syndrome, which was defined strictly in accordance with the criteria of the National Cholesterol Education Program Adult Treatment Panel III. ${ }^{5}$

The laboratory tests included serum liver tests (aspartate aminotransferase [AST], alanine aminotransaminase [ALT], gammaglutamyl transpeptidase $[\gamma \mathrm{GT}]$ and alkaline phosphatase [ALP]), hepatitis B serological tests (anti-HBc IgM and $\operatorname{IgG}$ ), hepatitis C serological tests (antibodies for hepatitis C) and total blood count. Serum fasting glucose (GLU), triglycerides (TGL), total cholesterol (CHL) and fractions (low-density lipoprotein [LDL], very low-density lipoprotein [VLDL] and high-density lipoprotein [HDL]) were also obtained. All the above tests were performed as part of the routine clinical analysis.

Abdominal ultrasound examination was carried out on all patients by one specialist on the same equipment (Sono Site 180),
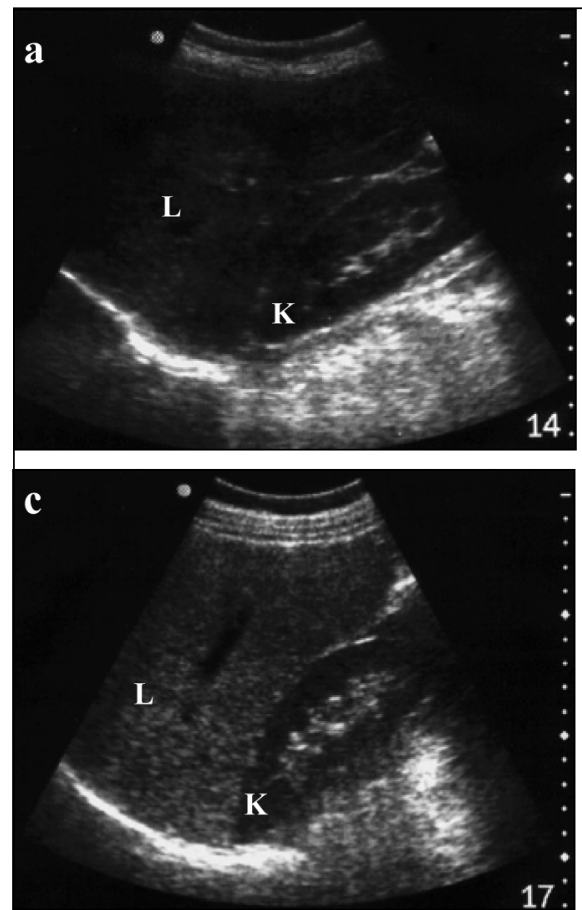

Figure 1. Sagittal ultrasound scans showing echo intensities in both liver parenchyma $(L)$ and renal cortex $(K)$. The panels represent cases in which liver steatosis was not observed (a), mild (b), moderate (c) and severe (d).
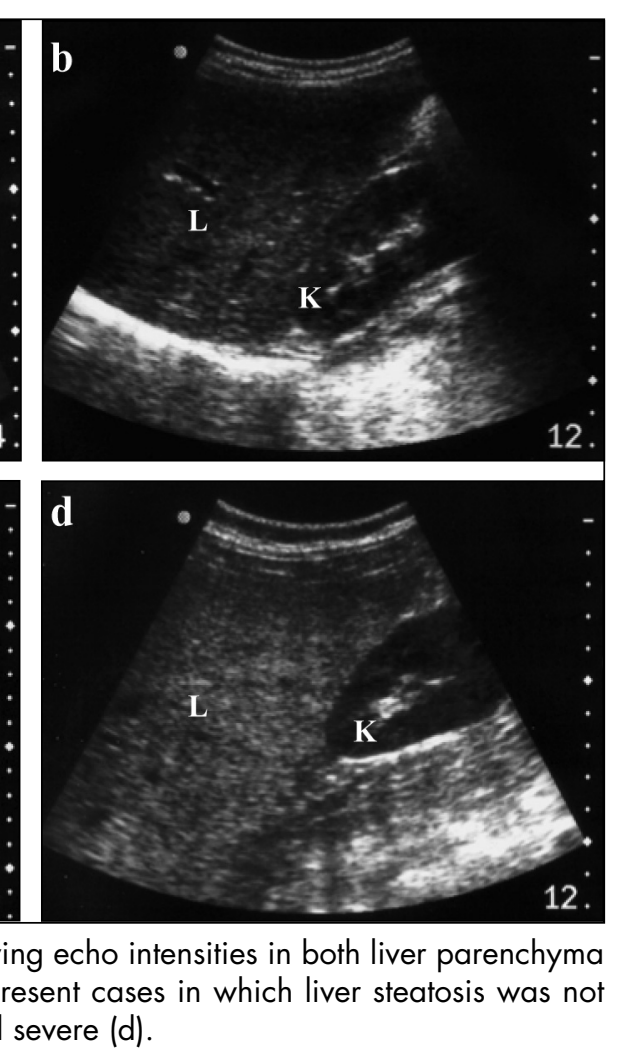

using a convex $3.5 \mathrm{MHz}$ probe. Sagittal hepatic sections encompassing longitudinal images of the right lobe of the liver and the ipsilateral kidney were obtained. Fatty infiltration was graded qualitatively into four classes according to subjective assessment of the contrast between the hepatic parenchyma and the renal cortex, in terms of echo intensity: ${ }^{6}$ non-observed (grade 0 ), mild steatosis (grade I), moderate steatosis (grade II) and severe steatosis (grade III) (Figure 1). NAFLD was defined as a fatty liver found on ultrasound examination of non-drinkers in the absence of the following: hematological macrocytosis (which would be suggestive of alcohol abuse), consumption of possible hepatotoxic drugs, symptomatic or asymptomatic hepatitis B and C infection, and clinical findings compatible with other liver disorders. No cases of focal fatty infiltration were observed in this study.

This study was approved by the Ethics Committee of the university in which the study was undertaken, and it was conducted in accordance with the provisions of the Helsinki Declaration. Only patients who gave their written consent were included.

The data were expressed as means \pm standard deviations (SD). Differences in continuous variables between groups were investigated with multivariate analysis using the Bonferroni correction. Categorical variables were analyzed by the chi-squared and Fisher exact tests. In all cases, $\mathrm{p}<0.05$ was taken to indicate significance.

REsults

Data from 38 individuals enrolled during the clinical screening were eliminated from the database for the following exclusion reasons: five due to excessive alcohol intake, three due to clinical findings suggestive of liver disease, two due to use of a potentially hepatotoxic drug (methyldopa), one due to confirmed presence of macrocytosis, 12 due to unavailability for laboratory tests and 15 due to reactivity to hepatitis $\mathrm{B}$ or $\mathrm{C}$. Thus, 139 subjects fulfilled the inclusion criteria: 20 males and 119 females of mean age 67.0 years $(S D=5.0)$ and age range from 55 to 85 years. The way in which the sample was constituted probably accounted for the differences regarding age, in which the men were older than the women.

The demographic and laboratory data are shown in Table 1 . The ranges of ALT, $\gamma \mathrm{GT}$, AST and ALP were 7-86, 5-91, 11-77 and 101-376 U/l, respectively. Abnormal levels of liver function markers were discovered in 29 patients $(20.9 \%)$. One patient $(0.7 \%)$ had abnormal AST alone (> $46 \mathrm{U} / \mathrm{l})$, i.e. presenting normal ALT, ALP and $\gamma$ GT; two patients $(1.4 \%)$ had abnormal ALT alone (> $50 \mathrm{U} / \mathrm{l}$ ); seven patients $(5.0 \%$ ) had abnormal ALP alone (> $300 \mathrm{U} / \mathrm{l})$; and thirteen patients $(9.4 \%)$ had abnormal $\gamma \mathrm{GT}$ alone (< $10 \mathrm{U} / \mathrm{l}: \mathrm{n}=8$; > $48 \mathrm{U} / \mathrm{l}: \mathrm{n}=5$ ). Incidental abnormal ALT ( $>50 \mathrm{U} / \mathrm{l}$ ) together with other markers was observed in two patients with AST elevation (1.4\%) and two other patients with $\gamma \mathrm{GT}$ elevation (1.4\%). Simultaneous abnormal ALP and $\gamma$ GT levels were also detected in two other cases (1.4\%). No cases of ALP levels below $70 \mathrm{U} / \mathrm{l}$ were observed. These clinical and laboratory results were consistent with a general good state of health among these patients, in terms of gastrointestinal appearance and functions.

NAFLD was found in $35.2 \%(n=49)$ of the 139 subjects. Most of the steatotic patients $(\mathrm{n}=25)$ presented echogenicity compatible with mild fatty accumulation, followed in frequency by the moderate $(\mathrm{n}=18)$ and severe $(n=6)$ phenotypes. No gender adjustments were made, because reports have usually described similar frequencies among men and women aged 55 years and over. ${ }^{7,8}$

To characterize the metabolic state of the group, the five components of metabolic syndrome were quantified. The vast majority 
of the patients presented severely elevated serum fat and arterial pressure levels (Table 1). The mean systolic and diastolic pressures were consistent with the observation that $74.8 \%$ of all the individuals had at least one abnormal measurement $(\geq 130$ or $\geq 85 \mathrm{mmHg}$, respectively). The hyperlipemic profile derived from the fact that respectively 75.5, 58.3 and $38.8 \%$ of the samples showed total, LDL and VLDL cholesterol levels above their normal upper limits (> 200, > 130 and > $30 \mathrm{mg} / \mathrm{dl}$ ). Accordingly, $40.3 \%$ of the subjects presented hypertriglyceridemia $(\geq 150 \mathrm{mg} / \mathrm{dl}$ ), whereas HDL cholesterol $<40 \mathrm{mg} / \mathrm{dl}$ for males and $<50 \mathrm{mg} / \mathrm{dl}$ for females (i.e. below the recommended levels) was observed in $24.5 \%$ of the group. Waist circumference exceeded the threshold for abdominal obesity ( $>102 \mathrm{~cm}$ for males and $>88 \mathrm{~cm}$ for females) in $38.1 \%$ of the patients. Only a small number of the patients $(10.8 \%)$ had glycemia levels $\geq 110 \mathrm{mg} / \mathrm{dl}$, i.e. above normal values. After age-adjustment analysis, none of the means showed significant changes.

Taking into account that four out of the five criteria for metabolic syndrome (fasting glucose, triglycerides, arterial pressure and waist circumference) were not influenced by gender in our analysis (Table 1), the whole group was considered together in estimating the frequency of metabolic syndrome. Under our conditions, roughly one in every four of these middle-aged and older adults (25.9\%) was diagnosed as presenting metabolic syndrome (i.e. three or more of the criteria fulfilled). Four criteria were found in $11.5 \%$ of our subjects, while all five criteria were fulfilled in $2.9 \%$. Only $10.8 \%$ of the patients did not satisfy any of the diagnostic criteria.

Taken together, the two most intense manifestations of NAFLD (II-III) presented higher levels of serum fasting glucose, total triglycerides and VLDL cholesterol than did the non-steatotic group (Table 2). It is important to draw attention to the fact that these serum metabolites were strong markers for metabolic syndrome, and that the nonparametric results confirmed an association $(\mathrm{p}<0.05)$ between the steatotic manifestation and the occurrence of the syndrome itself (Table 3). This latter association can be illustrated by the fact that subjects with metabolic syndrome presented a ratio of steatotic to non-steatotic cases that was more than twice as large (ratio $=1.0)$ as the ratio presented by subjects without the syndrome $($ ratio $=0.4)$. No liver function markers showed predictive value for any of the fatty liver phenotypes.
Table 1. Anthropometric, clinical and laboratory data on the subjects

\begin{tabular}{|c|c|c|c|c|}
\hline & $\begin{array}{c}\text { Men } \\
(n=20)\end{array}$ & $\begin{array}{l}\text { Women } \\
(\mathrm{n}=119)\end{array}$ & $\begin{array}{l}\text { All cases } \\
(n=139)\end{array}$ & $\mathbf{p}^{*}$ \\
\hline Age (years) & $71.0 \pm 5.8$ & $66.6 \pm 5.7$ & $67.0 \pm 5.0$ & $<0.05$ \\
\hline$W C(\mathrm{~cm})$ & $96.4 \pm 7.9$ & $88.1 \pm 10.2$ & $89.2 \pm 10.3$ & NS \\
\hline SAP (mmHg) & $144.5 \pm 22.0$ & $135.0 \pm 17.0$ & $136.4 \pm 18.2$ & NS \\
\hline DAP $(\mathrm{mmHg})$ & $88.0 \pm 11.0$ & $83.0 \pm 11.0$ & $83.7 \pm 11.3$ & NS \\
\hline TGL (mg/dl) & $138.3 \pm 66.7$ & $156.3 \pm 68.0$ & $153.7 \pm 67.8$ & NS \\
\hline $\mathrm{CHL}(\mathrm{mg} / \mathrm{dll})$ & $193.8 \pm 29.4$ & $230.5 \pm 40.5$ & $225.2 \pm 41.1$ & $<0.001$ \\
\hline LDL (mg/dl) & $119.5 \pm 25.8$ & $142.4 \pm 36.6$ & $139.1 \pm 36.1$ & $<0.01$ \\
\hline VLDL (mg/dl) & $27.8 \pm 13.3$ & $30.7 \pm 11.8$ & $30.3 \pm 12.0$ & NS \\
\hline $\mathrm{HDL}(\mathrm{mg} / \mathrm{dl})$ & $46.6 \pm 10.2$ & $58.2 \pm 13.0$ & $56.5 \pm 13.2$ & $<0.001$ \\
\hline GLU (mg/dl) & $89.8 \pm 22.5$ & $90.5 \pm 28.6$ & $90.4 \pm 27.7$ & NS \\
\hline AST (U/I) & $27.0 \pm 7.7$ & $26.2 \pm 10.0$ & $26.3 \pm 9.6$ & NS \\
\hline ALT (U/I) & $24.2 \pm 9.3$ & $21.7 \pm 12.4$ & $22.1 \pm 12.0$ & NS \\
\hline ALP (U/I) & $206.2 \pm 55.2$ & $196.0 \pm 56.8$ & $197.5 \pm 56.5$ & NS \\
\hline$\gamma \mathrm{GT}(\mathrm{U} / \mathrm{I})$ & $33.2 \pm 23.9$ & $21.7 \pm 12.0$ & $23.4 \pm 14.8$ & $<0.05$ \\
\hline
\end{tabular}

${ }^{*}$ Comparison between male and female subjects. $W C=$ waist circumference; $S A P=$ systolic arterial pressure; $D A P=$ diastolic arterial pressure; $T G L=$ triglycerides; $C H L=$ total cholesterol; $L D L=$ low density lipoprotein; $V L D L=$ very low density lipoprotein; $H D L=$ high density lipoprotein; $G L U=$ fasting serum glucose; $A S T=$ aspartate aminotransferase; $A L T=$ alanine aminotransferase, $A L P=$ alkaline phosphatase; $\gamma G T=$ gamma-glutamyl transpeptidase; NS = non-significant.

Table 2. Mean anthropometric and clinical features, and mean levels of metabolic and liver function markers according to the stage of the non-alcoholic fatty liver disease (NAFLD)

\begin{tabular}{lccc} 
& \multicolumn{3}{c}{ NAFLD phenotype } \\
\cline { 2 - 4 } & $\mathbf{0}$ & $\mathbf{I}$ & $\mathbf{I I - I I I}$ \\
$(\mathbf{n = 9 0 )}$ & $(\mathbf{n = 2 5 )}$ & $65.7 \pm 5.2$ \\
\hline Age (years-old) & $67.7 \pm 5.4$ & $65.5 \pm 5.8$ & $89.4 \pm 11.0$ \\
WC (cm) & $88.1 \pm 9.9$ & $92.8 \pm 10.7$ & $137.5 \pm 22.7$ \\
SAP (mmHg) & $135.8 \pm 17.9$ & $137.4 \pm 14.9$ & $84.2 \pm 11.2$ \\
DAP (mmHg) & $83.4 \pm 11.9$ & $84.4 \pm 9.2$ & $102.0 \pm 38.8^{*}$ \\
GLU (mg/dl) & $87.2 \pm 25.1$ & $90.6 \pm 21.9$ & $231.9 \pm 37.2$ \\
CHL (mg/dl) & $223.8 \pm 44.5$ & $224.0 \pm 31.4$ & $140.5 \pm 30.9$ \\
LDL (mg/dl) & $140.0 \pm 39.5$ & $134.8 \pm 27.6$ & $35.0 \pm 12.0^{*}$ \\
VLDL (mg/dl) & $27.9 \pm 10.4$ & $34.4 \pm 15.2^{*}$ & $57.0 \pm 14.1$ \\
HDL (mg/dl) & $56.9 \pm 13.6$ & $54.7 \pm 11.2$ & $187.6 \pm 93.6^{\dagger}$ \\
TGL (mg/dl) & $139.7 \pm 52.1$ & $171.8 \pm 76.0$ & $27.0 \pm 13.2$ \\
AST (U/l) & $26.6 \pm 9.3$ & $24.8 \pm 6.6$ & $23.7 \pm 16.5$ \\
ALT (U/l) & $21.9 \pm 11.9$ & $21.0 \pm 6.5$ & $191.5 \pm 57.5$ \\
ALP (U/l) & $203.5 \pm 56.0$ & $181.5 \pm 55.5$ & $26.2 \pm 14.4$ \\
rGT (U/l) & $23.3 \pm 16.3$ & $20.8 \pm 8.0$ & \\
\hline
\end{tabular}

${ }^{*} p<0.05$ when compared with the non-steatotic (0) group; ${ }^{\dagger} p<0.01$ when compared with the non-steatotic (0) group $W C=$ waist circumference; $S A P=$ systolic arterial pressure; $D A P=$ diastolic arterial pressure; $G L U=$ fasting serum glucose $C H L=$ total cholesterol; $L D L=$ low density lipoprotein; $V L D L=$ very low density lipoprotein; $H D L=$ high density lipoprotein, $T G L=$ triglycerides; $A S T=$ aspartate aminotransferase; $A L T=$ alanine aminotransferase; $A L P=$ alkaline phosphatase; $\gamma G T=$ gamma-glutamyl transpeptidase.

Table 3. Comparison of frequencies of non-alcoholic fatty liver disease (NAFLD) phenotypes between subjects with and without metabolic syndrome. Observed and predicted frequencies are displayed together with percentages (between parentheses), for each group

\begin{tabular}{cccccc}
\hline & & & $\begin{array}{c}\text { With metabolic } \\
\text { syndrome } \\
\mathbf{n = 3 6}\end{array}$ & $\begin{array}{c}\text { Without metabolic } \\
\text { syndrome } \\
\mathbf{n = 1 0 3}\end{array}$ & $\mathbf{p}^{*}$ \\
\hline \multirow{5}{*}{ NAFLD frequencies } & count & $18(50.0)$ & $72(69.9)$ & \\
& I & expected count & $23.3(64.7)$ & $66.7(64.7)$ & \\
& & count & $11(30.6)$ & $14(13.6)$ & $<0.05$ \\
& II- & copected count & $6.5(18.1)$ & $18.5(18.0)$ & \\
& III & expected count & $7(19.4)$ & $17(16.5)$ & \\
\hline
\end{tabular}

${ }^{*} \chi^{2}=6.03 ;$ degrees of freedom $(d f)=2$ 
Discussian

The main finding from this study was that approximately one in every three of these Brazilian middle-aged and older adults enrolled in the study presented findings compatible with cryptogenic NAFLD. Moreover, the present report indicates a prevalence of NAFLD that is notably higher than what was derived from studies carried out elsewhere on younger cohorts. Compared with data in the literature, the present study suggests that the frequency of idiopathic NAFLD among these healthy, predominantly elderly Brazilians was greater than among healthy, predominantly middle-aged Korean, ${ }^{7}$ Japanese ${ }^{9}$ and Italian ${ }^{10}$ cohorts. Studies conducted in populations with westernized lifestyles have found prevalence of liver steatosis of approximately $20 \% .^{1,11,12}$ This greater prevalence corroborates other reports $s^{4,7,10}$ in which greater age is described as an important risk factor for fatty liver disease, and it may indicate that the social and health conditions inherent to developing countries intensify the frequency of NAFLD. In addition, these results allow the elderly to be included in the general statement that liver steatosis is frequent even in the absence of other data suggestive of hepatic disorders. ${ }^{10,13}$

The presence of NAFLD was significantly associated with a spectrum of findings compatible with impaired insulin action. A series of physiopathological, clinical and laboratory investigations have supported the notion that insulin resistance has a central role in the pathogenesis of $\mathrm{NAFLD}^{14-16}$. In the present report, states of insulin resistance were expressed by means of fasting glucose levels. This is a rather crude indicator for insulin action, but it is of practical use for large surveys. Moreover, NAFLD has also been shown to correlate with the heterogeneous condition known as metabolic syndrome, which is broadly related to insulin resistance. Despite correlation with the syndrome as a whole, the present results most likely underscore the actual level of associations between the fatty liver phenotype and each component of metabolic syndrome, since this study was not designed to exclude subjects undergoing cardiovascular, hypolipemic and hypoglycemic pharmacotherapy.

It is likely that the high visceral fat content observed, which was reflected by the proportion of individuals with waist circumference measurements greater than the acceptable limits (almost $40 \%$ of the subjects), acted as a predisposing element in the development of NAFLD, as described elsewhere. ${ }^{17}$ Therefore, another contribution from the present report consists of emphasizing that the association between NAFLD and features of metabolic syndrome may be extended to the whole Brazilian population. Moreover, these findings indicate that increased fat delivery and/or sustained endogenous biosynthesis in the liver are the most likely physiopathogenic mechanisms underlying the onset of NAFLD under our conditions, to the detriment of the hypothesis of diminished lipoprotein secretion. ${ }^{18}$ This is because an accumulation of deep abdominal fat may lead to increased delivery of fatty acids to the liver, followed by increased synthesis and secretion rates for triglycerides and VLDL particles, and by the onset of liver steatosis in susceptible individuals. These hypotheses need to take into account human genomic and nutritional heterogeneity, which deserve consideration.

The major criticisms that may be made of the present study probably lie in the impossibility of ruling out covert or intermittent alcohol consumption, or excessive liver echogenicity unrelated to fatty infiltration. Nonetheless, the absence of clinical and biochemical evidence for alcohol abuse among the subjects selected lessened the possibility of recent or chronic alcohol use. Moreover, in alcoholic liver disease, abstinence usually leads to rapid resolution of the fatty infiltrate. ${ }^{19}$ In addition, screening for reactivity to hepatitis B and C probably prevented the inclusion of individuals presenting cirrhotic conditions. Because of the costs involved in this type of survey, it was not possible to enlarge the sample used in the study. Nonetheless, since most of Brazil's aging and elderly population share similar socioeconomic standards, characterized by low income, low schooling levels and poor nutritional conditions, ${ }^{20-22}$ we would tend towards considering our findings to be illustrative of the scenario in this country.

Brazil is a developing country in which the efforts to evaluate the prevalence of and burden caused by liver conditions may be considered insufficient. To the authors' knowledge, there is a lack of systematic assessments of NAFLD on either a local or a national scale. This is the first report aimed at evaluating the occurrence of such conditions among the aging population of Brazil.

\section{CONCLUSIONS}

Taken together, our results indicate that the prevalence of NAFLD among Brazilians aged 55 years and over is greater than what is seen elsewhere. Also, our findings implicated metabolic disorders that are compatible with metabolic syndrome presenting the steatotic phenotype. The present study is a report from an ongoing prospective study on the outcomes from dietary pattern and associated metabolic disorders, with regard to health status within the aging population of Brazil. 
1. Akbar DH, Kawther AH. Non-alcoholic fatty liver disease and metabolic syndrome: what we know and what we don't know. Med Sci Monit. 2006;12(1):RA23-6.

2. Day CP, James OF. Hepatic steatosis: innocent bystander or guilty party? Hepatology. 1998;27(6):1463-6

3. Younossi ZM. Nonalcoholic fatty liver disease. Curr Gastroenterol Rep. 1999;1(1):57-62.

4. Bellentani S, Tiribelli C, Saccoccio G, et al. Prevalence of chronic liver disease in the general population of northern Italy: the Dionysos Study. Hepatology. 1994;20(6):1442-9.

5. Expert Panel on Detection, Evaluation, and Treatment of High Blood Cholesterol in Adults. Executive Summary of The Third Report on the National Cholesterol Education Program (NCEP) Expert Panel on Detection, Evaluation, And Treatment of High Blood Cholesterol In Adults (Adult Treatment Panel III). JAMA. 2001;285(19):2486-97.

6. Osawa H, Mori Y. Sonographic diagnosis of fatty liver using a histogram technique that compares liver and renal cortical echo amplitudes. J Clin Ultrasound. 1996;24(1):25-9.

7. Park SH, Jeon WK, Kim SH, et al. Prevalence and risk factors of non-alcoholic fatty liver disease among Korean adults. J Gastroenterol Hepatol. 2006;21(1 Pt 1):138-43.

8. Mulhall BP, Ong JP, Younossi ZM. Non-alcoholic fatty liver disease: an overview. J Gastroenterol Hepatol. 2002;17(11):1136-43.

9. Nomura H, Kashiwagi S, Hayashi J, Kajiyama W, Tani S, Goto M. Prevalence of fatty liver in a general population of Okinawa, Japan. Jpn J Med. 1988;27(2):142-9.
10. Bellentani S, Saccoccio G, Masurti F, et al. Prevalence of and risk factors for hepatic steatosis in Northern Italy. Ann Intern Med. 2000;132(2):112-7.

11. Falck-Ytter Y, Younossi ZM, Marchesini G, McCullough AJ Clinical features and natural history of nonalcoholic steatosis syndromes. Semin Liver Dis. 2001;21(1):17-26.

12. Ruhl CE, Everhart JE. Epidemiology of nonalcoholic fatty liver Clin Liver Dis. 2004;8(3):501-19, vii.

13. Marchesini G, Bugianesi E, Forlani G, et al. Nonalcoholic fatty liver, steatohepatitis, and the metabolic syndrome. Hepatology. 2003;37(4):917-23.

14. Angulo P, Alba LM, Petrovic LM, Adams LA, Lindor KD, Jensen MD. Leptin, insulin resistance, and liver fibrosis in human nonalcoholic fatty liver disease. J Hepatol. 2004;41(6):943-9.

15. Angulo P, Lindor KD. Non-alcoholic fatty liver disease. Gastroenterol Hepatol. 2002;17 Suppl:S186-90.

16. Kim HJ, Kim HJ, Lee KE, et al. Metabolic significance of nonalcoholic fatty liver disease in nonobese, nondiabetic adults. Arch Intern Med. 2004;164(19):2169-75.

17. Sabir N, Sermez Y, Kazil S, Zencir M. Correlation of abdomina fat accumulation and liver steatosis: importance of ultrasonographic and anthropometric measurements. Eur J Ultrasound. 2001;14(2-3):121-8

18. Bacon BR, Farahvash MJ, Janney CG, Neuschwander-Tetri BA. Nonalcoholic steatohepatitis: an expanded clinical entity. Gastroenterology. 1994;107(4):1103-9.
19. Bashist B, Hecht HL, Harley WD. Computed tomographic demonstration of rapid changes in fatty infiltration of the liver. Radiology. 1982;142(3):691-2

20. Chaimowicz $\mathrm{F}$. A saúde dos idosos brasileiros às vésperas do século XXI: problemas, projeçōes e alternativas. [Health of Brazilian elderly population on the eve of the 21 st century: current problems, forecasts and alternatives]. Rev Saúde Pública = J Public Health. 1997;31(2):184-200.

21. Nóbrega OT, Melo GF, Karnikowski MGO. Pattern of drug prescribed for community-residing middle-aged and older adults from the outskirts of Brasília. Rev Bras Ciênc Farm 2005;41(2):271-7.

22. Forattini OP. Qualidade de vida e meio urbano. A cidade de São Paulo, Brasil. [Quality of life and urban environment. São Paulo city, Brazill. Rev Saúde Pública = J Public Health 1991;25(2):75-86.

Acknowledgments: Thanks are due to Willian Khalil for technical support and logistic help within the laboratory.

Sources of funding: This work was supported by a grant from Universidade Católica de Brasília, from 2003 to 2004

Conflict of interest: None

Date of first submission: December 1, 2006

Last received: November 14, 2007

Accepted: November 23, 2007

\section{AUTHDR INFDRMATIDN}

Mauro Karnikowski, MD MSc Associate Professor Universidade Aberta da Terceira Idade (UnATI), Universidade Católica de Brasília (UCB), Taguatinga, Federal District, Brazil.

Cláudio Córdova, PhD. Titular professor, stricto sensu postgraduate program on Physical Education, Universidade Católica de Brasília (UCB), Taguatinga, Federal District, Brazil.

Ricardo Jaco de Oliveira, PhD. Titular professor, stricto sensu postgraduate program on Physical Education, Universidade Católica de Brasília (UCB), Taguatinga, Federal District, Brazi

Margô Gomes de Oliveira Karnikowski, PhD. Titular professor, stricto sensu postgraduate program on Gerontology, Universidade Católica de Brasília (UCB), Taguatinga, Federal District, Brazil.

Otávio de Tolêdo Nóbrega, PhD. Titular professor, stricto sensu postgraduate program in Gerontology, Universidade Católica de Brasília (UCB), Taguatinga, Federal District, Brazil.

Author contributions: Mauro Karnikowski substantially contributed towards designing and conducting the study. Cláudio Córdova significantly contributed towards ana lyzing and interpreting the results. Ricardo J. de Oliveira lyzing and interpreting the results. Ricardo J. de Oliveira
significantly contributed towards interpreting the results and significantly contributed towards interpreting the results and
proofreading the manuscript. Margô G. O. Karnikowski substantially contributed towards designing and conducting the study. Otávio T. Nóbrega substantially contributed

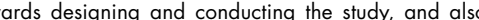
towards analyzing and interpreting the results. All authors participated in preparing the manuscript.

\section{Address for correspondence:}

Otávio de Tolêdo Nóbrega

Programa de Pós-Graduação Stricto Sensu em

Gerontologia.

Universidade Católica de Brasilia.

Q.S. 07 - lote 01 - EPCT - Águas Claras

Taguatinga (DF) - Brasil - CEP 72030-170

Tel. (+55 61) $33569693-$ Cel. $(+5561) 8451$

3718 - Fax. (+55 61) 33563010

E-mail: nobrega@ucb.br

Copyright @ 2007, Associação Paulista de Medicina
RESUMD

\section{Esteatose hepática não-alcóolica e síndrome metabólica em brasileiros idosos e de meia-idade}

CONTEXTO E OBJETIVOS: Esteatose hepática não-alcoólica (EHNA) constitui entidade clínico-patológica caracterizada por acúmulo focal ou difuso de gordura no parênquima hepático de pacientes que negam consumo abusivo de álcool. Este estudo avaliou a freqüência de EHNA entre indivíduos idosos e de meiaidade residentes em comunidade no Distrito Federal. Foi investigada a associação de EHNA com síndrome metabólica (SM) e seus componentes individuais.

TIPO DE ESTUDO E LOCAL: Estudo seccional realizado com 139 indivíduos com idade igual ou superior a 55 anos.

MÉTODOS: EHNA foi diagnosticada por protocolo clínico para exclusão de indivíduos com sinais de de sordens hepáticas, consumo abusivo de álcool e influência hepatotóxica de medicamentos. Fenótipos de EHNA foram classificados com base na ecogenecidade sonográfica. Síndrome metabólica foi definida com base no critério do National Cholesterol Education Program Adult Treatment Panel III. Exames laboratoriais foram realizados para complementar a avaliação clínica bem como diagnosticar SM.

RESULTADOS: EHNA encontrava-se presente em 35,2\% dos indivíduos. Em conjunto, os dois fenótipos mais intensos correlacionaram-se com níveis aumentados de glicemia, triglicérides e VLDL lipoproteína (muito baixa densidade) colesterol em jejum. Síndrome metabólica foi diagnosticada em 25,6\% dos casos. Além da associação entre EHNA e variáveis discretas representativas da síndrome metabólica, análise não paramétrica confirmou a relação $(p<0,05)$ entre a manifestação esteatótica e a entidade sindrômica.

CONCLUSÕES: Comparado com a literatura, este estudo revelou freqüência de EHNA idiopática em brasileiros idosos e de meia-idade maior que a descrita em outros estudos. Nossos achados sugerem que metabolismo glicêmico anormal conjugado a um maior aporte lipídico e/ou biossíntese exacerbada no fígado são prováveis mecanismos fisiopatogênicos da EHNA na população estudada.

PALAVRAS-CHAVE: Esteatose hepática. Idoso. Meia-idade. Síndrome x metabólica. Brasil. 